\section{Effect of Four Hormonal Con- traceptives on Lipid Profile Under Real Conditions of Use After 6 Months of Treatment}

\author{
Beltran DA ${ }^{1 *}$, Crespo $\mathrm{AB}^{2}$, Valle $\mathrm{SG}^{3}$ and Iglesias $\mathrm{AG}^{4}$ \\ ${ }^{1}$ Vicalvaro Municipal Health Centre Madrid-Salud. Madrid Council, Madrid, \\ Spain
}

${ }^{2}$ Veterinary School, Complutense University of Madrid, Spain

${ }^{3}$ Community pharmacy, Master of Toxicology, University of Salamanca, Spain

${ }^{4}$ Department of Obstetrics, Gynaecology and Paediatrics, Faculty of Medicine, University of Salamanca, Spain

\begin{abstract}
This study has been designed with the aim of assessing the impact of six months of treatment with four hormonal contraceptives using different routes of administration (oral, transdermal and vaginal) on the plasma levels of cholesterol, triglycerides, HDL cholester-
\end{abstract} ol and LDL cholesterol.

\section{Study design}

This is an observational, prospective, randomised and concurrent study amongst women of childbearing age (18-45 years), under normal clinical practice conditions, who attend a family planning appointment to request a hormonal contraceptive and do not meet any of the study's exclusion criteria and have no contraindications for the use of hormonal contraceptive methods.

\section{Materials and methods}

324 women were included using a group randomisation system with the following distribution: 64 were randomised to the transdermal Norelgestromin group, 61 to the transvaginal-release Etonogestrel group, 67 to the oral Chlormadinone group, 69 to the oral

*Corresponding author: David Angel Beltran, Vicalvaro Municipal Health Centre Madrid-Salud. Madrid Council, Madrid, Spain, Tel: +34 914671882; E-mail: beltrangine@gmail.com

Citation: Beltran DA, Crespo AB, Valle SG, Iglesias AG (2020) Effect of Four Hormonal Contraceptives on Lipid Profile Under Real Conditions of Use After 6 Months of Treatment. J Food Sci Nutr 6: 065.

Received: May 18, 2020; Accepted: May 23, 2020; Published: May 30, 2020

Copyright: () 2020 Beltran DA, et al. This is an open-access article distributed under the terms of the Creative Commons Attribution License, which permits unrestricted use, distribution, and reproduction in any medium, provided the original author and source are credited.
Drospirenone group and 63 to a control group in which the subjects were not given any type of treatment. Plasma levels of cholesterol, triglycerides, HDL cholesterol and LDL cholesterol were determined before treatment and six months after taking the hormone steroid treatment, except in the case of the control group which was not give any medication.

\section{Results}

A statistically significant reduction of LDL cholesterol was found in the treatment group that received oral Chlormadinone and in the control group. On the contrary, this value increased in the other treatment groups, although this was not of statistical significance.

Keywords: Coagulation parameters; Hormonal contraceptives; Platelet; Venous tromboembolism

\section{Introduction}

The association of Hormonal Contraceptives (HC) and increased risk of cardiovascular disease and of Venous Thromboembolism (VTE) has been demonstrated in different studies [1,2], with evidence of a direct relation between this risk and the dose of the oestrogen component in the formulation $[3,4]$.

In this respect, there has been a great emphasis in the past decades on the influence of plasma lipoproteins as a cardiovascular risk factor, to such an extent that any abnormal lipid profile was associated with increased cardiovascular risk.

It is widely accepted that the oestrogen component has a positive effect on the lipid profile, and thus, the higher the oestrogen dose in the preparation, higher is the positive effect on lipoproteins [5-8] (Figure 1). The evolution of contraceptives has tended to reduce the oestrogen/progestogen ratio, which has been counteracted by a reduction in the progestogen dose, leading to lower androgenicity. Preparations containing second-generation progestogens have a more negative effect on the lipid profile in relation to HDL levels, in comparison with those that contain third-generation progestogens. This difference is reduced when the progestogen and accompanying oestrogen doses are lowered (Table 1). The untoward effects of progestogen lead to a rise in LDL-cholesterol and apoprotein B, and a fall in HDL cholesterol and apoprotein A, all of which leads in turn to an atherogenic profile.

In this respect it has been demonstrated that Norgestimate, Desogestrel and Gestodene increase HDL-C (lipoprotein protectors) but it is not known whether these biochemical changes are important from a clinical point of view [9-11]. Engel et al. [12], performed coronary angiography in women who had suffered a myocardial infarction and found that $36 \%$ of the women who had used oral contraceptives had diffuse atherosclerosis, while $79 \%$ of those who did not use oral contraceptives also had it, concluding that in women with previous myocardial infarction who were taking oral contraceptives, the infarction was not of atherosclerotic origin, but rather of thrombotic origin. This viewpoint supports the hypothesis put forward by Lobo et al. [13], that micro-dose oral contraceptives, including last-generation progestogens, afford heart protection. 


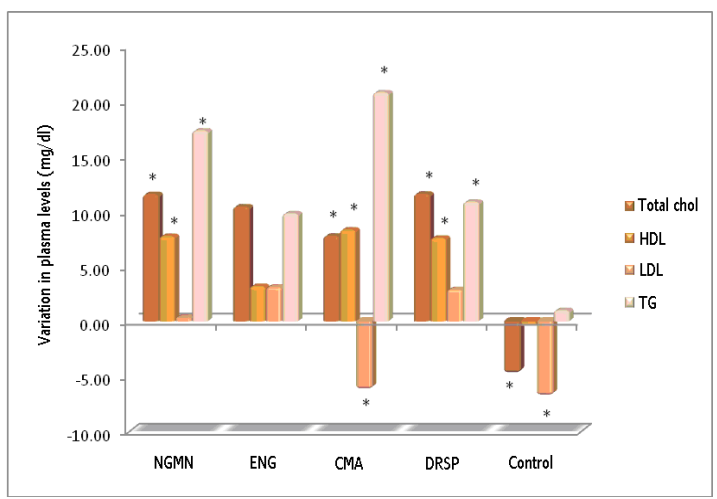

Figure 1: Influence of different $\mathrm{CHCs}$ on the lipid profile $(* \mathrm{p}<0.05)$

\begin{tabular}{|c|c|c|c|c|c|}
\hline & VLDL & TG & LDL & HDL & Apoprotein A \\
\hline High-dose oestrogens & 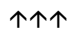 & 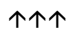 & & 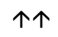 & 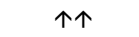 \\
\hline Low-dose oestrogens & 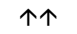 & 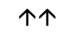 & & $\uparrow$ & $\uparrow$ \\
\hline $\begin{array}{l}\text { 2nd generation pro- } \\
\text { gestogens }\end{array}$ & $\downarrow$ & $\downarrow$ & $\uparrow$ & 个/-- & $\downarrow$ \\
\hline $\begin{array}{l}\text { 3rd generation pro- } \\
\text { gestogens }\end{array}$ & -- & -- & 个/-- & 个/-- & $\downarrow$ \\
\hline
\end{tabular}

Table 1: Effect of steroids on the lipid profile [5-8].

Low-dose contraceptives have no effect on total cholesterol and its fractions, despite reducing the progestogen/oestrogen ratio, since the type of progestogen has been modified (it is less androgenic) and the dose has also been reduced $[5,14]$.

In this study we used low-dose HC, varying the progestogen component and route of administration as authorised in recent years on the Spanish market. Thus, the following combinations of $\mathrm{HC}$ were given for 6 months:

- Transdermal route (once weekly administration): We used a Transdermal Patch (TRS) containing $6 \mathrm{mg}$ of Norelgestromin $(\mathrm{NGMN}) / 0.600 \mathrm{mg}$ of Ethinyl Estradiol (EE), with daily release of $0.203 \mathrm{mg}$ NGMN / $0.020 \mathrm{mg}$ EE

- Vaginal route: we used a Vaginal Release System (VRS) containing $11.7 \mathrm{mg}$ of Etonogestrel (ENG) and $2.7 \mathrm{mg}$ of EE. The ring releases an average of $0.012 \mathrm{mg}$ of ENG and $0.015 \mathrm{mg}$ of EE respectively, every 24 hours, for 3 weeks.

\section{- Oral route:}

Combined HC containing $2 \mathrm{mg}$ of Chlormadinone Acetate (CMA) and $0.030 \mathrm{mg}$ of EE.

Combined HC containing 3mg of Drospirenone (DRSP) and $0.030 \mathrm{mg}$ of EE.

\section{Methods}

\section{Study design}

The study scrupulously followed the recommendations of the Declaration of Helsinki (Hong Kong, 1989), European Good Clinical Practice Guides, and all participants were duly informed in writing, and provided their consent before commencing the study.
The women were randomised into 5 groups. 4 of these groups were treatment groups: NGNM group (TRS, $0.120 \mathrm{mg}$ NGMN/ $0.02 \mathrm{mg}$ EE); ENG group (VRS, $0.120 \mathrm{ENG}$ and $0.015 \mathrm{mg}$ EE); CMA group (oral, 2mg CMA/ 0.030mg EE); DRSP group (oral, 3mg DRSP/ $0.030 \mathrm{mg} \mathrm{EE}$ ); and a control group (which was not given any $\mathrm{CHC}$ ).

The contraceptive was administered on the first day following menstruation, and each patient was informed of the correct method of administering each $\mathrm{CHC}$.

The study was conducted in the gynaecology clinic at the Vicalvaro Municipal Health Centre in Madrid (Spain) between October 2008 and February 2009.

The study inclusion criteria were: Women of childbearing age (1845 years), without any contraindications for having hormonal contraceptives prescribed, who were not planning to become pregnant during the duration of the study (6 months) and who attended the gynaecology clinic requesting a hormonal contraceptive method in the case of the patients in the treatment groups, or for a routine checkup, not having used any hormonal contraceptive method for 6 months prior to commencing the study (control group).

The study exclusion criteria included contraindicated use of $\mathrm{CHC}$, age under 18 or over 45 years old, women who might want to become pregnant within 8 months, patients who did not agree to undergo clinical and laboratory tests at the intervals defined in the study protocol, and women who referred to poor compliance with the established dose regime in their contraceptive history.

The study was planned to last 6 months and entailed 2 visits: A baseline visit and a final visit.

The following procedures were scheduled at the baseline visit: medical history, cervical-vaginal cytology, transvaginal ultrasound, verification of normal laboratory test values with regard to lipid profile and blood biochemistry, recording of blood pressure, height and weight, and calculation of Body Mass Index (BMI).

After 6 months of treatment, a second visit was scheduled in order to assess the following parameters: treatment follow-up, medical history, transvaginal ultrasound, evolution of laboratory values, recording of blood pressure, height and weight, calculation of BMI, compliance with medication regime, as well as an assessment of any adverse events derived from the use of the CHC.

\section{Laboratory tests}

Blood samples were obtained through venipuncture. Approximately $12 \mathrm{ml}$ of blood were taken and distributed as follows: $3 \mathrm{ml}$ in a glass test tube containing $0.05 \mathrm{ml}$ of $8 \%$ EDTA for haematology; $4 \mathrm{ml}$ in a glass test tube without anticoagulant for biochemistry. A Coulter autoanalyser was used for the blood count and a Siemens ADVIA ${ }^{\circledR}$ 1650 Chemistry System autoanalyser was used for biochemistry.

Lyphochek ${ }^{\circledR}$ and Assayed Chemistry Control (Biorad) were used as reference controls for the different laboratory values.

The specific laboratory values that were determined for the lipid profile parameters were: Total cholesterol (g/dL); HDL cholesterol (g/ $\mathrm{dL})$; LDL cholesterol $(\mathrm{g} / \mathrm{dL})$, triglycerides $(\mathrm{g} / \mathrm{dL})$.

We also calculated the atherogenicity index in each subject in the treatment groups and in the control group. 
Citation: Beltran DA, Crespo AB, Valle SG, Iglesias AG (2020) Effect of Four Hormonal Contraceptives on Lipid Profile Under Real Conditions of Use After 6 Months of Treatment. J Food Sci Nutr 6: 065.

\section{Statistical analysis}

We assessed the influence of the four $\mathrm{OHC}$ on the lipid parameters. All parameters have been summarised, with respective descriptive statistics, mean and standard deviation.

We used Student's t-test to compare the biochemistry parameters. We used SPSS v.15.0 statistical package for the statistical analysis of data.

Statistical significance was considered as a value of $\mathrm{p}<0.05$.

\section{Results}

\section{Distribution of study subjects}

A total of 324 women of childbearing age were included. They were randomised to the following groups: EE/NGMN ( $n=64)$; EE/ $\operatorname{ENG}(n=62)$; EE/CMA $(n=68)$; EE/DRSP $(n=70)$; Control $(n=64)$.

During the 6 months that the study lasted, there were no drop-outs for adverse effects, protocol breaches or non-compliance with inclusion criteria.

\section{Baseline characteristics}

Baseline demographic data included age, weight, height, BMI and age at first menstruation (menarche) (Table 2). It can be observed that there were no differences between the different study groups.

\section{Lipid parameters}

The data for the lipid parameters assessed in this study are shown in table 3 .

The group given EE/NGMN through TRS (transdermal release system) underwent a mean increase of $11.55 \mathrm{mg} / \mathrm{dl}$ in total cholesterol. Their HDL cholesterol values, in turn, underwent a mean increase of $7.74 \mathrm{mg} / \mathrm{dl}$. LDL cholesterol levels remained almost unchanged, unlike triglyceride levels, which underwent a mean increase of $17.32 \mathrm{mg} /$ $\mathrm{dl}$ at the end of the study period.

On the other hand, the EE/ENG treatment group, administered through VRS (vaginal release system) also showed a small increase in total cholesterol values, of $5.26 \mathrm{mg} / \mathrm{dl}$. HDL and LDL cholesterol values at the end of the study hardly changed at all in comparison with the baseline values. A slight upward trend was observed in the mean triglyceride value, of $7.49 \mathrm{mg} / \mathrm{dl}$.

With regard to the women included in the oral EE/CMA treatment group, a small increase was found in total cholesterol values, of $7.77 \mathrm{mg} / \mathrm{dl}$. HDL cholesterol values underwent a mean increase of $8.32 \mathrm{mg} / \mathrm{dl}$. There was a noteworthy fall in mean LDL cholesterol values from the start to the end of the study, of $6.2 \mathrm{mg} / \mathrm{dl}$. On the contrary, triglyceride values increased $20.79 \mathrm{mg} / \mathrm{dl}$.

When analysing the group of women who were given the oral preparation containing ethinyl estradiol and drospirenone, they were found to have an increase in total cholesterol of $7.66 \mathrm{mg} / \mathrm{dl}$. The HDL cholesterol level increased $6.4 \mathrm{mg} / \mathrm{dl}$ at the end of the six-month treatment period. The end LDL cholesterol values were similar to those obtained in the first test. Triglyceride values rose minimally, by $8.49 \mathrm{mg} / \mathrm{dl}$.

Amongst the women who were not subjected to exogenous steroid hormone action (control group), there was a minimal fall in total cholesterol levels of $4.75 \mathrm{mg} / \mathrm{dl}$. The most notable finding in the second test results in this group of women was that the HDL cholesterol and triglyceride values remained unaltered in comparison with the baseline tests. However, the LDL cholesterol values decreased by $6.78 \mathrm{mg} /$ $\mathrm{dl}$ in comparison with the initial values, even though these women were not given any treatment.

\section{Discussion}

Contraceptive measures are not a modern practice. Efforts to limit reproduction are as ancient as sexual relations themselves. Contraceptives are one of the most commonly-used synthetic substances worldwide in preventing pregnancy. They are not risk free, however, and appropriate medical assessment is required before starting to take them.

Combined hormonal contraceptives are composed of two substances, regardless of the route of administration that is chosen. One is a synthetic (not natural) oestrogen. The commonest is ethinyl estradiol and, less frequently, mestranol. The metabolism of this compound varies from person to person and in different populations. At the same dose, positive and negative effects can be highly variable [15-17]. During the course of the broad experience that has been gained with these compounds, great importance has been given to the dose of the oestrogen component, and its relationship with undesired side effects, such as thromboembolism and circulatory problems [17-19].

The second component is gestagen or progestogen. This compound has undergone great changes in the last 20 years, because new products have been developed with lower doses, leading to a significant reduction in side effects, such as androgenic manifestations and modifications in the lipid profile [20-23].

Older contraceptives had a high dose of progestogens and were associated with adverse changes in the lipid profile [7,24]: Decreased HDL-C and increased LDL-C, creating atherogenic conditions [25]. Oestrogens in themselves cause an increase in HDL-C and lower LDL-C, and therefore the lipid profile depends on the balance between the effects of oestrogen and progestogen.

\begin{tabular}{|c|c|c|c|c|c|}
\hline & EE/NGMN (n=62) & EE/ENG (n=60) & EE/CMA (n=68) & EE/DRSP (n=70) & Control (n=64) \\
\hline Age (years) & $28 \pm 6.15$ & $28.77 \pm 13.18$ & $29.79 \pm 7.23$ & $28.51 \pm 6.20$ & $33.66 \pm 5.86$ \\
\hline Weight (kg) & $62.38 \pm 13.18$ & $60.14 \pm 11.93$ & $60.81 \pm 8.53$ & $61.36 \pm 8.27$ & $64.00 \pm 11.79$ \\
\hline Height (cm) & $181.66 \pm 8.14$ & $131.13 \pm 22.68$ & $161.44 \pm 6.64$ & $162.26 \pm 6.04$ & $161.63 \pm 6.16$ \\
\hline BMI: & $23.31 \pm 3.78$ & $22.68 \pm 3.92$ & $23.03 \pm 2.72$ & $23.14 \pm 3.17$ & $24.13 \pm 3.96$ \\
\hline Menarche (years) & $12.34 \pm 1.3$ & $12.77 \pm 1.64$ & $12.26 \pm 1.5$ & $12.66 \pm 1.02$ & $12.66 \pm 1.4$ \\
\hline
\end{tabular}

Table 2: Baseline demographic data. 
Citation: Beltran DA, Crespo AB, Valle SG, Iglesias AG (2020) Effect of Four Hormonal Contraceptives on Lipid Profile Under Real Conditions of Use After 6 Months of Treatment. J Food Sci Nutr 6: 065.

\begin{tabular}{|c|c|c|c|c|c|c|c|}
\hline & & & Mean & Min & Max & Standard Dev. & $\mathbf{p}$ \\
\hline \multirow[t]{8}{*}{ EE/NGMN (n=62) } & Tot chol & Start & 183.74 & 99 & 250 & 39.62 & 0.00055 \\
\hline & & 6 cycles & 195.29 & 118 & 275 & 34.68 & \\
\hline & HDL-Chol & Start & 59.61 & 40 & 81 & 10.10 & 0.00000 \\
\hline & & 6 cycles & 67.35 & 46 & 96 & 11.65 & \\
\hline & LDL-Chol & Start & 112.68 & 37 & 200 & 35.05 & 0.88517 \\
\hline & & 6 cycles & 113.06 & 37 & 204 & 29.88 & \\
\hline & TG & Start & 82.26 & 25 & 159 & 32.47 & 0.76883 \\
\hline & & 6 cycles & 99.58 & 33 & 211 & 47.17 & \\
\hline \multirow[t]{8}{*}{ EE/ENG $(\mathrm{n}=60)$} & Tot chol & Start & 179.97 & 116 & 252 & 32.05 & 0.25729 \\
\hline & & 6 cycles & 185.23 & 89 & 260 & 44.28 & \\
\hline & HDL-Chol & Start & 62.84 & 42 & 105 & 13.38 & 0.40696 \\
\hline & & 6 cycles & 64.26 & 44 & 103 & 17.40 & \\
\hline & LDL-Chol & Start & 104.77 & 55 & 174 & 24.27 & 0.95225 \\
\hline & & 6 cycles & 104.97 & 45 & 184 & 33.37 & \\
\hline & TG & Start & 77.90 & 38 & 170 & 31.57 & 0.07470 \\
\hline & & 6 cycles & 85.39 & 56 & 180 & 35.77 & \\
\hline \multirow[t]{8}{*}{$\mathrm{EE} / \mathrm{CMA}(\mathrm{n}=68)$} & Tot chol & Start & 177.79 & 131 & 265 & 32.34 & 0.01784 \\
\hline & & 6 cycles & 185.56 & 116 & 259 & 35.16 & \\
\hline & HDL-Chol & Start & 62.09 & 42 & 91 & 11.19 & 0.00000 \\
\hline & & 6 cycles & 70.41 & 36 & 112 & 17.03 & \\
\hline & LDL-Chol & Start & 103.32 & 59 & 158 & 28.51 & 0.03868 \\
\hline & & 6 cycles & 97.12 & 39 & 150 & 28.51 & \\
\hline & TG & Start & 78.06 & 40 & 200 & 34.06 & 0.00000 \\
\hline & & 6 cycles & 98.85 & 40 & 219 & 45.01 & \\
\hline \multirow[t]{8}{*}{ EE/DRSP $(n=70)$} & Tot chol & Start & 174.97 & 106 & 238 & 33.49 & 0.10900 \\
\hline & & 6 cycles & 182.63 & 115 & 262 & 44.12 & \\
\hline & HDL-Chol & Start & 63.66 & 34 & 101 & 19.07 & 0.00011 \\
\hline & & 6 cycles & 70.06 & 41 & 112 & 21.74 & \\
\hline & LDL-Chol & Start & 98.40 & 56 & 143 & 22.42 & 0.87503 \\
\hline & & 6 cycles & 98.94 & 48 & 187 & 30.47 & \\
\hline & TG & Start & 77.54 & 29 & 206 & 35.65 & 0.01645 \\
\hline & & 6 cycles & 86.03 & 37 & 220 & 40.05 & \\
\hline \multirow[t]{8}{*}{ Control $(n=64)$} & Tot chol & Start & 182.78 & 138 & 228 & 24.13 & 0.08242 \\
\hline & & 6 cycles & 178.03 & 140 & 214 & 21.06 & \\
\hline & HDL-Chol & Start & 59.97 & 36 & 79 & 9.75 & 0.66525 \\
\hline & & 6 cycles & 59.50 & 37 & 80 & 9.19 & \\
\hline & LDL-Chol & Start & 110.03 & 71 & 165 & 22.37 & 0.00334 \\
\hline & & 6 cycles & 103.25 & 58 & 140 & 17.79 & \\
\hline & TG & Start & 83.72 & 40 & 183 & 35.24 & 0.84350 \\
\hline & & 6 cycles & 84.72 & 31 & 199 & 40.90 & \\
\hline
\end{tabular}

Table 3: The effect of study treatment on lipid and lipoprotein profiles.

It is very likely that the ethinyl estradiol in oral contraceptives directly protects coronary arteries from atherogenesis, inhibiting LDL-C in blood vessel walls [25]. It is believed that third-generation progestogens have a neutral action on lipids and therefore, combined oral contraceptives containing progestogens would have a positive effect on lipid changes [25].

In this study, the products that we analysed had a similar quantity of EE, belonging to the so-called low-dose CHC group, and we varied the progestogen dose and route of administration. A correct balance between the $\mathrm{EE}$ and progestogen content in the preparation is very important in order to minimise the impact on the lipid profile [26].
Randomised clinical trials that are available at present have been conducted on small sample groups, and do not compare risks between women taking $\mathrm{OHC}$ and those who do not, but between women taking different types of OC. Some studies have found statistically significant increases in different biochemistry parameters, but within normal values.

Evidences obtained from first-generation OCs cannot be extrapolated to third-generation preparations that are used nowadays, with ethinyl estradiol doses that are six times lower and combined with radically different progestogens [19,27]. In general, the actions of synthetic steroids are very different when oestrogens or progestogens 
Citation: Beltran DA, Crespo AB, Valle SG, Iglesias AG (2020) Effect of Four Hormonal Contraceptives on Lipid Profile Under Real Conditions of Use After 6 Months of Treatment. J Food Sci Nutr 6: 065.

are used on their own or in combination. Ethinyl estradiol causes an increase in HDL, a reduction in LDL plasma levels, and increased VLDL, and TGL to a lesser extent [28-30]. In general, progestogens reduce VLDL and HDL fractions in plasma and increase LDLs [2830].

However, there are very significant differences between the different types of progestogens. The strongest atherogenic action is found in 19-nortestosterone derivatives (norethisterone and lynestrenol). On the contrary, the least impact is presented by hydroxyprogesterone derivatives (cyproterone acetate) and third-generation progestogens [20-23]. As a consequence, the global effect of OCs depends, theoretically, on the combination of the EE dose and the type and dose of the progestogen.

Oestrogens act on HDLs by means of two mechanisms: by suppressing hepatic lipase activity, leading to a reduction in HDL2 conversion into HDL3, and by increasing apoprotein A synthesis [30-32]. On the contrary, androgenic progestogens stimulate hepatic lipase activity. These mechanisms explain why an increase in oestrogen-induced increase in HDLs can be counteracted by the progestogenic component $[33,34]$. That is why OCs in current use contain third-generation progestogens, offering a clearly positive balance in HDL metabolism because they do not neutralise the beneficial effects of EE.

The mechanism by which androgenic progestogens increase LDL values is still not clear. Theoretically, the way these progestogens stimulate hepatic lipase activity should facilitate VLDL conversion into LDL $[33,34]$. This mechanism, together with the EE-induced stimulation in VLDL production, could result in increased LDL values. Contraceptive preparations containing third-generation progestogens has a lesser impact on the lipid profile.

OHC action on VLDLs and TGs represent one of the most important aspects in the way OCs influence lipid metabolism. The majority of studies have found an increase in TG and VLDL plasma values in eminently oestrogenic preparations, as a result of the increased VLDL product and reduced clearance rate induced by EE [33]. OHCs containing 19-nortestosterone-derivative progestogens have a palliative action on this effect.

Recent studies have demonstrated with sufficient evidence that OCs do not significantly increase lipoprotein A plasma values, and elevated lipoprotein A is clearly associated with ischaemic diseases.

In this study, after analysing total cholesterol values, we found a minimal increase in all groups except the control group, which showed a slight, insignificant fall [5,14] (Figure 1). This minimum impact on total cholesterol levels does not have a clinical repercussion in healthy women, and it confirms the results obtained in similar studies for the following combinations: $0.120 \mathrm{mg} \mathrm{NGMN} / 0.02 \mathrm{mg}$ EE in TRS format [35], 0.120 ENG and $0.015 \mathrm{mg}$ EE in VRS [36,37], $2 \mathrm{mg} \mathrm{CMA} / 0.030 \mathrm{mg}$ EE orally [38] and with the oral combination of 3mg DRSP/ 0,030mg EE [39,40].

In our study the biggest increase in total cholesterol was found in the Drospirenone and Norelgestromin groups, with a common increase for both of $11.5 \mathrm{mg} / \mathrm{dl}$. The smallest increase was found in the vaginal ring group, with a mean of $5.5 \mathrm{mg} / \mathrm{dl}$. These values are of statistical significance $(\mathrm{p}<0.05)$, but will not be clinically relevant in healthy women. Furthermore, the minimum increases in cholesterol levels match previously published studies on this type of CHC $[35,39,40]$.

With regard to the HDL figures, a small increase was observed in all treatment groups, and the highest values were found in those who took Drospirenone and Norelgestromin, with a figure of $7 \mathrm{mg} / \mathrm{dl}$ (Figure 1).

In relation to repercussion in LDL cholesterol values, changes were minimal in all treatment groups. The biggest reduction was found in women taking Chlormadinone, with a value of $6.21 \mathrm{mg} / \mathrm{dl}$.

The impact on triglycerides shows an increase in all treatment groups. The maximum value was found in the Chlormadinone group, with an increase of $20.7 \mathrm{mg} / \mathrm{dl}$, and the minimum value was found in the Etonogestrel group, with a value of $9.8 \mathrm{mg} / \mathrm{dl}$. In all study compounds it was confirmed that $\mathrm{CHCs}$ have a negative impact on triglyceride values, regardless of their route of administration [35-40].

Although it is suggested that the low-dose oral contraceptives that are used at present, combined with third-generation progestogens, have a clearly positive balance because they do not neutralise the beneficial action of ethinyl estradiol on high density lipoproteins, it is also acknowledged that androgenic progestogens stimulate the activity of hepatic lipase, leading to reduced HDL and decreasing apoprotein A synthesis. These mechanisms would explain why an ethinyl estradiol-induced increase in HDL could be counteracted by the progestogenic component, which also causes an increase in low density lipoproteins [41].

These modifications in the lipid profile have a minimal or nil clinical impact, although it should be remembered these treatments are potentially prescribed over a long period of time.

\section{Conclusion}

In view of the results obtained from this study and previous studies, we can recommend that in a healthy population there is little evidence to support the need for systematic determination, either in new users or in women who are already taking them. On the contrary, it is essential to assess this in women with established cardiovascular disease or with multiple risk factors (arterial hypertension, obesity, smokers, family history of premature heart disease).

On the contrary, combined hormonal contraceptives are contraindicated in women with ischaemic heart disease and hyperlipidaemia, even if the latter is controlled with medication. They are relatively contraindicated in women with isolated hyperlipidaemia without other associated cardiovascular risk factors.

OCs with third-generation progestogens are not recommended if there is hypertriglyceridaemia, since they lead to increased triglyceride plasma levels. It appears that hypertriglyceridaemia is related to an increase in prothrombotic factors and a reduction in fibrinolysis.

In our study, the oral combination EE/CMA was the $\mathrm{CHC}$ that causes the least impact on the lipid profile.

\section{References}

1. Middeldorp S (2009) Epidemiology of hormone-related venous thromboembolism. Thromb Res 123: 65-69. 
Citation: Beltran DA, Crespo AB, Valle SG, Iglesias AG (2020) Effect of Four Hormonal Contraceptives on Lipid Profile Under Real Conditions of Use After 6 Months of Treatment. J Food Sci Nutr 6: 065.

2. Shufelt CL, Merz CNB (2009) Contraceptive hormone use and cardiovascular disease. J Am Coll Cardio 153: 221-231.

3. Gerstman BB, Piper JM, Tomita DK, Ferguson WJ, Stadel BV, et al. (1991) Oral contraceptive estrogen dose and the risk of deep venous thromboembolic disease. Am J Epidemiol 133: 32-37.

4. Nessa A, Latif SA, Siddiqui NI (2006) Risk of cardiovascular diseases with oral contraceptives. Mymensingh Med J 15: 220-224.

5. Godsland IF, Crook D (1994) Update on the metabolic effects of steroidal contraceptives and their relationship to cardiovascular disease risk. Am J Obstet Gyneco 1170: 1528-1536.

6. Godsland IF, Crook D, Wynn V (1990) Low-dose oral contraceptives and carbohydrate metabolism. Am J Obstet Gynecol 163: 348-353.

7. Krauss RM, Burkman RT (1992) The metabolic impact of oral contraceptives. Am J Obstet Gyneco 1167: 1177-1184.

8. Sondheimer SJ (1991) Update on the metabolic effects of steroidal contraceptives. Endocrinol Metab Clin North Am 20: 911-923.

9. Corson SL (1990) Efficacy and clinical profile of a new oral contraceptive containing norgestimate. U.S. clinical trials. Acta Obstet Gynecol Scand Suppl 152: 25-31.

10. Fotherby K (1990) Update on lipid metabolism and oral contraceptive. $\mathrm{Br}$ J Fam Plann 15: 23-26.

11. Robinson GE, Bounds W, Mackie IJ, Stocks J, Burren T, et al. (1990) Changes in metabolism induced by oral contraceptives containing desogestrel and gestodene in older women. Contraception 42: 263-273.

12. Engel HJ, Engel E, LichtlenPR (1983) Coronary atherosclerosis and myocardial infarction in young women -- role of oral contraceptives. Eur Heart J 4: 1-8.

13. Lobo RA, Skinner JB, Lippman JS, Cirillo SJ (1996) Plasma lipids and desogestrel and ethinylestradiol: A meta-analysis. Fertil Steril 65: 11001109.

14. Godsland IF, Crook D, Simpson R, Proudler T, Felton C, et al. (1990) The effects of different formulations of oral contraceptive agents on lipid and carbohydrate metabolism. N Engl J Med 323: 1375-1381.

15. Bagshaw S (1995) The combined oral contraceptive. Risks and adverse effects in perspective. Drug Saf 12: 91-96.

16. Carr BR, Ory H (1997) Estrogen and progestin components of oral contraceptives: relationship to vascular disease. Contraception 55: 267-272.

17. Thorogood M, Villard-Mackintosh L (1993) Combined oral contraceptives: Risks and benefits. Br Med Bull 49: 124-139.

18. Gallo MF, Nanda K, Grimes DA, Lopez LM, Schulz KF (2008) 20 microg versus $>20$ microgestrogen combined oral contraceptives for contraception. Cochrane Database Syst Rev 003989.

19. Kiley J, Hammond C (2007) Combined oral contraceptives: A comprehensive review. Clin Obstet Gyneco 150: 868-877.

20. Erkkola R, Landgren BM (2005) Role of progestins in contraception. Acta Obstet Gynecol Scand 84: 207-216.

21. Rowlands S (2003) Newerprogestogens. J Fam Plann Reprod Health Care 29: $13-16$

22. Sitruk-Ware R (2004) Pharmacological profile of progestins. Maturitas 47: 277-283.

23. Sitruk-Ware R (2006) Newprogestagens for contraceptive use. Hum Reprod Update 12: 169-178.
24. Carr BR, Ory H (1997) Estrogen and progestin components of oral contraceptives: Relationship to vascular disease. Contraception 55: 267-272.

25. ESHRE Capri Workshop Group (2006) Hormones and cardiovascular health in women: Hum Reprod Update 12: 483-497.

26. Endrikat J, Klipping C, Cronin M, Gerlinger C, Ruebig A, et al. (2002) An open label, comparative study of the effects of a dose-reduced ora contraceptive containing 20 [mu]g ethinylestradiol and $100[\mathrm{mu}] \mathrm{g}$ levonorgestrel on hemostatic, lipids, and carbohydrate metabolism variables. Contraception 65: 215-221.

27. Erkkola R (2007) Recent advances in hormonal contraception. Curr Opin Obstet Gynecol 19: 547-553.

28. Sojo-Aranda I, Cortes-Gallegos V (1990) Pharmacodynamics of synthetic estrogens. A review. Ginecol Obstet Mex 58: 277-283.

29. Szafran H, Smielak-Korombel W (1998) The role of estrogens in hormonal regulation of lipid metabolism in women. Przegl Lek 55: 266-270.

30. Upton GV (1990) Lipids, cardiovascular disease, and oral contraceptives: A practical perspective. Fertil Steril 53: 1-12.

31. Herrington DM, Parks JS (2004) Estrogen and HDL: All that Glitters Is not Gold. Arterioscler Thromb Vasc Biol 24: 1741-1742.

32. Wahl P, Walden C, Knopp R, Hoover J, Wallace R, et al. (1983) Effect of estrogen/progestin potency on lipid/lipoprotein cholesterol. N Engl J Med 308: 862-867.

33. Tikkanen MJ (1996) Estrogens, progestins and lipid metabolism. Maturitas 23: 51-55.

34. Tuohimaa P, BlSuer M, Pasanen S, Passinen S, Pekki A, et al. (1996) Mechanisms of action of sex steroid hormones: Basic concepts and clinical correlations. Maturitas 23: 3-12.

35. Creasy GW, Fisher AC, Hall N, Shangold GA (2003) Transdermal contraceptive patch delivering norelgestromin and ethinyl estradiol. Effects on the lipid profile. J Reprod Med 48: 179-186.

36. Elkind-Hirsch KE, Darensbourg C, Ogden B, Ogden LF, Hindelang P (2007) Contraceptive vaginal ring use for women has less adverse metabolic effects than an oral contraceptive. Contraception 76: 348-356.

37. Tuppurainen M, Klimscheffskij R, Venhola M, Dieben T (2004) The combined contraceptive vaginal ring (NuvaRing) and lipid metabolism: A comparative study. Contraception 69: 389-394.

38. Cagnacci A, Ferrari S, Tirelli A, Zanin R, Volpe A (2009) Insulin sensitivity and lipid metabolism with oral contraceptives containing chlormadinone acetate or desogestrel: A randomized trial. Contraception 79: 111-116.

39. Gaspard U, Endrikat J, Desager JP, Buicu C, Gerlinger C, et al. (2004) A randomized study on the influence of oral contraceptives containing ethinylestradiol combined with drospirenone or desogestrel on lipid and lipoprotein metabolism over a period of 13 cycles. Contraception 69: 271278.

40. Klipping C, Marr J (2005) Effects of two combined oral contraceptives containing ethinyl estradiol 20 Microg combined with either drospirenone or desogestrel on lipids, hemostatic parameters and carbohydrate metabolism. Contraception 71: 409-416.

41. Gillings D, Koch G (1991) The application of the principle of intention to treat to the analysis of clinical trials. Drug Inf J 25: 411-424. 


\section{H}

Advances In Industrial Biotechnology | ISSN: 2639-5665

Advances In Microbiology Research | ISSN: 2689-694X

Archives Of Surgery And Surgical Education | ISSN: 2689-3126

Archives Of Urology

Archives Of Zoological Studies | ISSN: 2640-7779

Current Trends Medical And Biological Engineering

International Journal Of Case Reports And Therapeutic Studies | ISSN: 2689-310X

Journal Of Addiction \& Addictive Disorders | ISSN: 2578-7276

Journal Of Agronomy \& Agricultural Science | ISSN: 2689-8292

Journal Of AIDS Clinical Research \& STDs | ISSN: 2572-7370

Journal Of Alcoholism Drug Abuse \& Substance Dependence | ISSN: 2572-9594

Journal Of Allergy Disorders \& Therapy | ISSN: 2470-749X

Journal Of Alternative Complementary \& Integrative Medicine | ISSN: 2470-7562

Journal Of Alzheimers \& Neurodegenerative Diseases | ISSN: 2572-9608

Journal Of Anesthesia \& Clinical Care | ISSN: 2378-8879

Journal Of Angiology \& Vascular Surgery | ISSN: 2572-7397

Journal Of Animal Research \& Veterinary Science | ISSN: 2639-3751

Journal Of Aquaculture \& Fisheries | ISSN: 2576-5523

Journal Of Atmospheric \& Earth Sciences | ISSN: 2689-8780

Journal Of Biotech Research \& Biochemistry

Journal Of Brain \& Neuroscience Research

Journal Of Cancer Biology \& Treatment | ISSN: 2470-7546

Journal Of Cardiology Study \& Research | ISSN: 2640-768X

Journal Of Cell Biology \& Cell Metabolism | ISSN: 2381-1943

Journal Of Clinical Dermatology \& Therapy | ISSN: 2378-8771

Journal Of Clinical Immunology \& Immunotherapy | ISSN: 2378-8844

Journal Of Clinical Studies \& Medical Case Reports | ISSN: 2378-8801

Journal Of Community Medicine \& Public Health Care | ISSN: 2381-1978

Journal Of Cytology \& Tissue Biology | ISSN: 2378-9107

Journal Of Dairy Research \& Technology | ISSN: 2688-9315

Journal Of Dentistry Oral Health \& Cosmesis | ISSN: 2473-6783

Journal Of Diabetes \& Metabolic Disorders | ISSN: 2381-201X

Journal Of Emergency Medicine Trauma \& Surgical Care | ISSN: 2378-8798

Journal Of Environmental Science Current Research | ISSN: 2643-5020

Journal Of Food Science \& Nutrition | ISSN: 2470-1076

Journal Of Forensic Legal \& Investigative Sciences | ISSN: 2473-733X

Journal Of Gastroenterology \& Hepatology Research | ISSN: 2574-2566
Journal Of Genetics \& Genomic Sciences | ISSN: 2574-2485

Journal Of Gerontology \& Geriatric Medicine | ISSN: 2381-8662

Journal Of Hematology Blood Transfusion \& Disorders | ISSN: 2572-2999

Journal Of Hospice \& Palliative Medical Care

Journal Of Human Endocrinology | ISSN: 2572-9640

Journal Of Infectious \& Non Infectious Diseases | ISSN: 2381-8654

Journal Of Internal Medicine \& Primary Healthcare | ISSN: 2574-2493

Journal Of Light \& Laser Current Trends

Journal Of Medicine Study \& Research | ISSN: 2639-5657

Journal Of Modern Chemical Sciences

Journal Of Nanotechnology Nanomedicine \& Nanobiotechnology | ISSN: 2381-2044 Journal Of Neonatology \& Clinical Pediatrics | ISSN: 2378-878X

Journal Of Nephrology \& Renal Therapy | ISSN: 2473-7313

Journal Of Non Invasive Vascular Investigation | ISSN: 2572-7400

Journal Of Nuclear Medicine Radiology \& Radiation Therapy | ISSN: 2572-7419

Journal Of Obesity \& Weight Loss | ISSN: 2473-7372

Journal Of Ophthalmology \& Clinical Research | ISSN: 2378-8887

Journal Of Orthopedic Research \& Physiotherapy | ISSN: 2381-2052

Journal Of Otolaryngology Head \& Neck Surgery | ISSN: 2573-010X

Journal Of Pathology Clinical \& Medical Research

Journal Of Pharmacology Pharmaceutics \& Pharmacovigilance | ISSN: 2639-5649

Journal Of Physical Medicine Rehabilitation \& Disabilities | ISSN: 2381-8670

Journal Of Plant Science Current Research | ISSN: 2639-3743

Journal Of Practical \& Professional Nursing | ISSN: 2639-5681

Journal Of Protein Research \& Bioinformatics

Journal Of Psychiatry Depression \& Anxiety | ISSN: 2573-0150

Journal Of Pulmonary Medicine \& Respiratory Research | ISSN: 2573-0177

Journal Of Reproductive Medicine Gynaecology \& Obstetrics | ISSN: 2574-2574

Journal Of Stem Cells Research Development \& Therapy | ISSN: 2381-2060

Journal Of Surgery Current Trends \& Innovations | ISSN: 2578-7284

Journal Of Toxicology Current Research | ISSN: 2639-3735

Journal Of Translational Science And Research

Journal Of Vaccines Research \& Vaccination | ISSN: 2573-0193

Journal Of Virology \& Antivirals

Sports Medicine And Injury Care Journal | ISSN: 2689-8829

Trends In Anatomy \& Physiology | ISSN: 2640-7752

Submit Your Manuscript: https://www.heraldopenaccess.us/submit-manuscript 